\title{
The association of DNA and stable catanionic amino acid-based vesicles ${ }^{\text {th }}$
}

\author{
Mónica Rosa ${ }^{\mathrm{a}, \mathrm{b}, *}$, María del Carmen Morán ${ }^{\mathrm{c}}$, Maria da Graça Miguel ${ }^{\mathrm{a}, 1}$, Björn Lindman ${ }^{\mathrm{a}, \mathrm{b}, 1}$ \\ ${ }^{a}$ Chemistry Department, Coimbra University, 3004-535 Coimbra, Portugal \\ b Physical Chemistry 1, Lund University, P.O. Box 124, 22100 Lund, Sweden \\ ${ }^{\mathrm{c}}$ Department of Surfactant Technology, IIQAB-CSIC, J. Girona 18-26, 08034 Barcelona, Spain
}

Received 28 August 2006; received in revised form 3 December 2006; accepted 28 December 2006

Available online 13 January 2007

This publication is dedicated to Professor Jarl B. Rosenholm, Department of Physical Chemistry, Åbo Akademi University, Finland on the occasion of his 60th birthday.

\begin{abstract}
Cationic surfactants associate strongly to DNA and compact but are often toxic. The interaction of some novel cationic amino acid-based surfactants, which may enhance transfection and appear to be nontoxic, is described. A cationic arginine-based surfactant, ALA, gives in combination with anionic surfactants spontaneously stable vesicles, and special attention is given to the association of these catanionic vesicles, with a net positive charge, to DNA. The ability of this surfactant alone to compact DNA is compared in fluorescence microscopy studies to classical cationic surfactants. Addition of DNA to a solution of the catanionic vesicles results in associative phase separation at very low vesicle concentrations; there is a separation into a precipitate and a supernatant solution, which is first bluish but becomes clearer as more DNA is added. From studies using cryogenic transmission electron microscopy (cryo-TEM) and small angle X-ray scattering it is demonstrated that there is a lamellar structure with DNA arranged within the surfactant bilayers. Analysis of the supernatant by means of proton nuclear magnetic resonance $\left({ }^{1} \mathrm{H}\right.$ NMR) showed that above the isoelectric point between ALA, anionic surfactant (sodium octyl sulfate, SOS) and DNA, anionic surfactant starts to be expelled from the bilayers on further incorporation of DNA. There appears to be a transition from a lamellar to a hexagonal liquid crystal structure when most of SOS has been expelled from the aggregate bilayers; at higher DNA-to-surfactant ratios, self-assembled SOS micelles and the excess of DNA added seem to coexist in solution. Regarding the phase-separating DNA-surfactant particles, cryo-TEM demonstrates a large and nonmonotonic variation of particle size as the DNA-surfactant ratio is varied, with the largest particles obtained in the vicinity of overall charge neutrality.
\end{abstract} (C) 2007 Elsevier B.V. All rights reserved.

Keywords: DNA; Catanionic vesicles; Biocompatible system

\section{Introduction}

Liposome-based systems have been used as biocompatible carriers of drugs, peptides, proteins and plasmid DNA, for pharmaceutical, cosmetic and biochemical purposes [1]. When applied for drug delivery, gene therapy, and immunization, the reduction of toxicity effects in sensitive organs becomes imper-

\footnotetext{
This work was submitted in March 2006 for inclusion in the special issue honoring Professor Rosenholm. However, due to unfortunate circumstances at the journal it was mislabeled and, therefore, not included there.

* Corresponding author at: Elan Corporation Monksland, Athlone County Westmeath, Ireland. Tel.: +353906495789; fax: +353906495809.

E-mail address: t-Monica.TorresRosa@elan.com (M. Rosa).

1 These senior authors much respect Jarl B. Rosenholm as a colleague and as a friend; Björn Lindman in particular thanks him for a close collaboration and for more than 30 years of fruitful interactions.
}

ative; toxicity effects are in particular encountered with cationic surfactants. These toxicity consequences can be avoided by designing new systems based on novel biocompatible and nontoxic surfactants and lipids.

A special type of vesicles, catanionic vesicles, are composed of a mixture of cationic and anionic surfactants and are known to form spontaneously in water [2-6]. Typically, because of the cationic surfactant, they may show toxicity. Studies on the interaction between DNA and lipid-based vesicles have for a long time been presented in the literature whereas studies on mixtures of catanionic vesicles and DNA are more recent [7-9]. Nevertheless, they all present a similar feature, a strong associative phase separation with precipitate formation [8]; the driving force for this strong association is the counterion release [10].

DNA packaging in the living cellular environment is a very important phenomenon. DNA compaction by poly-amines, like 
spermidine and spermine, are examples of events that occur in cells and are believed to be important in regulation of cell proliferation and differentiation. In the literature one can find many studies of DNA compaction in aqueous solution; DNA molecules are known to undergo a discrete conformational transition from an extended to a collapsed state by interacting with single $[9,11-14]$ or double $[13,15]$ chain cationic amphiphiles, as well as many others, namely: gemini surfactants [16], poly-amines [17,18], neutral $[19,20]$ or negatively charged polymers [19]; a coexistence interval exists where both conformations are present. Although the mechanism of DNA compaction has been a subject of many studies it is not yet fully understood.

Since one of our main motivations consists in the development of new non-toxic biocompatible and biodegradable [21] systems, we introduced in this study an amino acid-based cationic surfactant, ALA, with an arginine head-group. Furthermore, toxicity studies (data to be published elsewhere) revealed that the incorporation of ALA in our catanionic vesicles system transformed them into cell viable systems, extending therefore their use to drug and gene delivery systems, as well as cosmetic and food formulations [22].

The physical chemistry aspects of the interaction of DNA with two different systems are explored in this paper. Firstly, we describe the interaction of DNA with ALA alone, at a single molecular level, where the conformational transition of individual DNA chains, from an extended to a collapsed state, has been followed by fluorescence microscopy on addition of ALA. The ability of ALA to compact DNA has been compared with that of other cationic surfactant systems [14]. Secondly, the interaction of DNA with a catanionic vesicle system composed of ALA, and sodium octyl sulfate, SOS, has been investigated. From an analysis of the supernatant we get a picture of the associative phase separation. The concentrated phase is investigated with respect to internal structure by small angle X-ray scattering (SAXS) and cryogenic transmission electron microscopy (cryo-TEM), the latter technique also providing information on particle size and shape.

\section{Experimental section}

\subsection{Materials}

Sodium octyl sulfate (SOS) was obtained from Merck and used as received; arginine- $N$-lauroyl amide dihydrochloride, ALA, is a divalent cationic surfactant (Fig. 1); its synthesis and physiochemical properties can be found in the literature $[21,23,24]$. Double stranded DNA (dsDNA) type XIV from herring testes and T2 DNA were purchased from Sigma and used as received. DNA type XIV was further investigated by gel electrophoresis to determine its molecular weight and was found to be polydisperse and have between 400 and 1000 base pairs, bp, with a center of the distribution at ca. 700 bp. All DNA concentrations were determined spectrophotometrically considering the molar extinction coefficient of DNA bases to be equal to $6600 \mathrm{M}^{-1} \mathrm{~cm}^{-1}$ [25]. The ratio between the measured absorbances at 260 and $280 \mathrm{~nm}$ of DNA stock solutions

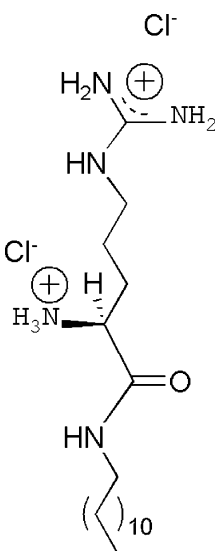

Fig. 1. Chemical structure of the amino acid-based cationic surfactant, ALA, used in this study. ALA stands for arginine- $N$-lauroyl amide dihydrochloride.

were found to be between 1.8 and 1.9, which suggested the absence of proteins [26]. The fluorescence dye, 4'-6-diamidino2-phenyl-indole (DAPI), and the antioxidant, 2-mercaptoethanol (ME) were purchased from Sigma. All concentrations are presented per charge. Water was purified using a Millipore Q system.

\subsection{Sample preparation}

Solutions of catanionic vesicles were prepared by making stock solutions of individual surfactants, combining them, at the desired composition, to a required amount of water, and mixing all components by simple hand agitation. The vesicle solutions had a total surfactant concentration of $1 \mathrm{wt} . \%$ with a molar charge ratio of ALA to SOS of 1.7. After solution preparation, solutions were left to equilibrate at room temperature for a few days.

Stock solutions of double stranded DNA were prepared at $1 \mathrm{mM} \mathrm{NaBr}$ and added to the vesicle solutions to achieve the required final concentration. For fluorescence microscopy studies, T2 DNA stock solutions were prepared in $10 \mathrm{mM}$ Tris-Cl buffer solution at $\mathrm{pH}$ 7.6.

Mixed solutions of DNA and ALA for FM studies were prepared in the presence of $4 \%(\mathrm{v} / \mathrm{v}) \mathrm{ME}$ and DAPI. The final concentrations used were: $0.5 \mu \mathrm{M}$ of DNA per phosphate and $0.5 \mu \mathrm{M}$ DAPI. Under these conditions, the binding number of the dye per DNA bp in an aqueous buffer solution is estimated to be equal to 0.05 and the persistence length of the DNA chain is expected to remain nearly the same as in the absence of DAPI [27]. ALA was added to the mixtures at the desired concentrations.

Mixed solutions of DNA and vesicles were prepared at different DNA to vesicle effective net charge ratios, $R=[\mathrm{DNA}] /\left[\mathrm{S}^{+}\right]_{\mathrm{eff}}$, where $\left[\mathrm{S}^{+}\right]_{\mathrm{eff}}$ is the effective cationic surfactant concentration, which is the difference between the ALA and SOS concentrations (concentrations determined per charge). The next step consisted in centrifuging all samples for $10 \mathrm{~min}$ at $4000 \mathrm{rpm}$. The supernatant was taken off by pipetting the upper part of the centrifuged samples. 


\subsection{Fluorescence microscopy}

The fluorescence microscopy study was performed as follows: the samples were illuminated with a UV-mercury lamp; the fluorescence images of single DNA molecules were observed using a Zeiss Axioplan microscope, equipped with a $100 \times$ oil-immersed objective lens, and digitized on a personal computer through a high-sensitive SIT video camera and an image processor, Argus-20 (Hamamatsu Photonics, Japan). The observations were carried out at $25^{\circ} \mathrm{C}$. Special care was taken to clean the microscope glasses (No. 0, Chance Propper, England) thoroughly before the observation to prevent DNA degradation, as well as precipitation to the glass surface [28].

\subsection{Turbidity measurements}

Turbidity measurements were performed for the vesicle solutions as well as for the supernatant of all the DNA-vesicle mixtures studied. All measurements were performed at room temperature, $25^{\circ} \mathrm{C}$. A Lambda14 UV/Visible spectrometer (Perkin Elmer) was used, at the wavelength of $350 \mathrm{~nm}$, using a $0.5 \mathrm{~cm}$ path length quartz cell.

\subsection{Cryogenic transmission electron microscopy}

Cryo-TEM is a powerful technique for direct visualization of colloidal aggregates in aqueous media, provided particle sizes range from $5-10 \mathrm{~nm}$ to $1 \mu \mathrm{m}$. Controlled sample preparation conditions are required: a controlled-environment vitrification system (CEVS), at controlled temperature (to prevent temperature changes) and humidity (to minimize water loss), was used [29]. Vitrified samples were prepared and imaged according to a procedure described in the literature [29-31]. A Philips CM 120 Bio-Twin microscope equipped with a post-column energy filter, using an Oxford CT3500 cryoholder and its workstation, was used. All images were recorded digitally through a CCD camera (Gatan MSC791).

\subsection{Small angle $X$-ray scattering}

The SAXS data were recorded with a Kratky compact smallangle system equipped with a position sensitive detector (OED $50 \mathrm{M}$ from Mbraun, Austria) containing 1024 channels of width $53.0 \mu \mathrm{m}$. A monochromator with a $10 \mu \mathrm{m}$-thick nickel filter was used to select the $\mathrm{Cu} \mathrm{K} \alpha$ radiation $(\lambda=1.542 \AA)$ provided by the generator, and a $1.5-\mathrm{mm} \mathrm{W}$ filter was used to protect the detector from the primary beam.

The generator, a Seifert ID-300 X-ray, was operating at $50 \mathrm{kV}$ and $40 \mathrm{~mA}$. A few milligrams of the sample were enclosed in a stainless steel sample holder with mica windows. The distance between the sample and detector was $277 \mathrm{~mm}$. The diffraction patterns were recorded at 25 and $37^{\circ} \mathrm{C}$. The temperature was maintained constant within $0.1^{\circ} \mathrm{C}$ by a Peltier element. The optics and the sample cell were both held under vacuum to minimize the scatter from air.

\subsection{Nuclear magnetic resonance}

${ }^{1} \mathrm{H}$ NMR spectra were recorded on a Bruker DMX 500 spectrometer operating at a frequency of $500 \mathrm{MHz}$ with a resolution of $0.25 \mathrm{~Hz}$. The pulse width used was $6 \mu \mathrm{s}$. The sample was kept at a constant temperature of $25^{\circ} \mathrm{C}$ and controlled to an accuracy of $\pm 0.5^{\circ} \mathrm{C}$. All samples were prepared as described in the sample preparation section with the exception that heavy water was used instead. This technique was used as an analytical tool to follow the composition changes in the supernatant as a function of $R$. Changes in the bandshape are important to follow since they are usually related with liquid crystal formation or phase transitions $[32,33]$. The data obtained from the spectra allow us to track events in the supernatant and, indirectly, learn about the composition of the concentrated phase.

\section{Results}

\subsection{Compaction of DNA by an amino acid-based surfactant}

The fluorescence microscopy approach allows the direct visualization of the individual DNA chains and thus to the monitoring of the overall conformational changes. In this way, Yoshikawa and coworkers $[9,11-20]$ have investigated the compaction of DNA induced by several cationic species, surfactants, lipids, polymers, etc. and it has become a central tool for investigating DNA-cosolute interactions.

DNA molecules in aqueous solution present an extended conformation, usually denoted as unfolded coil conformation. As cationic entities are added to this unfolded conformation, DNA is known to undergo a discrete transition into a collapsed state, denoted as folded globule state. This coil to globule transition is characterized by a coexistence region where both coils and globules can be found in solution $[9,11,12,20]$. As mentioned previously, one can find in the literature studies with many different kinds of compacting agents [9,11-20]. All these studies present basically the same main features, mentioned above for cationic entities in general: a coil to globule transition passing through a coexistence region with both conformations, with progressive changes in the two populations.

Fig. 2 illustrates the conformational behavior of T2 DNA in the presence of ALA (chemical structure in Fig. 1). For sake of the discussion we also plotted the literature results for a series of conventional cationic surfactants, with different tail length [14]. Up to a concentration of ALA of $10^{-5} \mathrm{M}$, DNA presents itself still in the extended conformation; as more ALA was added, $[\mathrm{ALA}]=1.5 \times 10^{-5} \mathrm{M}$, both extended coils and globules could be seen. As we continue adding cationic surfactant we see that the amount of coils gradually decreases, giving rise to a population of only globules from an ALA concentration of $2.0 \times 10^{-4} \mathrm{M}$. Thus, the coexistence between unfolded and folded DNA molecules appears to be within the concentration range from $1.5 \times 10^{-5}$ until $2.0 \times 10^{-4} \mathrm{M}$. At higher ALA concentrations, when folded DNA molecules were the only ones visualized, we noted that they tend to be excluded from the bulk aqueous phase onto the glass surface, suggesting a drastic 


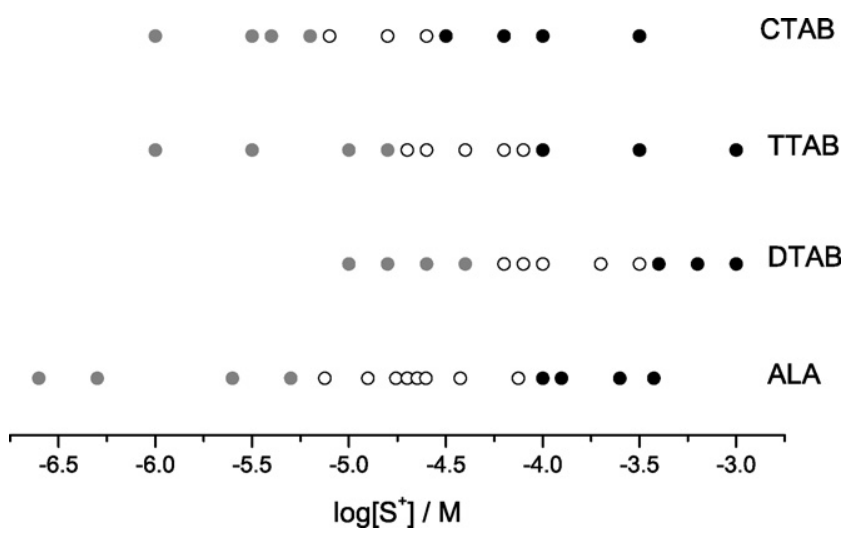

Fig. 2. The dependence of the conformational change of single T2 DNA molecules on concentration of ALA. $[\mathrm{DNA}]=0.5 \mu \mathrm{M} /$ phosphate in aqueous Tris- $\mathrm{Cl}$ buffer ( $\mathrm{pH}$ 7.6). Grey filled circles correspond to unfolded molecules and black filled circles correspond to folded ones, whereas open circles corresponds to the coexistence between the two DNA states. Data of CTAB, TTAB and DTAB was taken, for comparison, from Ref. [14]. $T=25^{\circ} \mathrm{C}$.

decrease in the solvent quality for the DNA-ALA complexes. This was noted by the increase of fluorescent precipitates seen near the glass surface.

In Fig. 3 one can see typical fluorescence micrographs illustrating DNA conformational changes as cationic agent is added. In this particular case, we have added ALA to DNA while it changes its conformation from coil (a) to globule (c), passing through a state of coexistence (b). DNA molecules in the unfolded state exhibit a translational and intramolecular Brownian motion in solution and they also present a blurring effect $[12,20]$, as can be observed in the same figure.

\subsection{DNA addition to the vesicle system}

The vesicle system used in this study consists of a mixture of an amino acid-based cationic surfactant, ALA, and an anionic surfactant, SOS, at a molar charge ratio ALA/SOS of 1.7 in 99 wt. \% of water. This surfactant system was characterized elsewhere [34]. It was found that it, in analogy with several other mixed cationic-anionic surfactant systems, presents a spontaneous formation of vesicles having a long-term stability; in fact they remain over our extended times of investigation suggesting that they may be thermodynamically stable. Our approach of using an amino acid-based single-tailed surfactant in the catanionic vesicle composition was based on the fact that ALA alone and the mixture of ALA and SOS presented cell viability percentages above $90 \%$ (results to be published); ALA has also been reported as being biodegradable [21].

DNA was added to the vesicle solutions at different ratios of DNA to net surfactant cationic charge concentrations, $R=[\mathrm{DNA}] /\left[\mathrm{S}^{+}\right]_{\mathrm{eff}}$, where $\left[\mathrm{S}^{+}\right]_{\mathrm{eff}}=[\mathrm{ALA}]-[\mathrm{SOS}]$; all concentrations in moles per charge. We are interested in the characterization both of the supernatant and of the precipitated complexes. The supernatant composition was used as an analytical tool from which we extracted information on changes of the composition of the concentrated phase as $R$ changes. For the precipitated complexes we also explore how
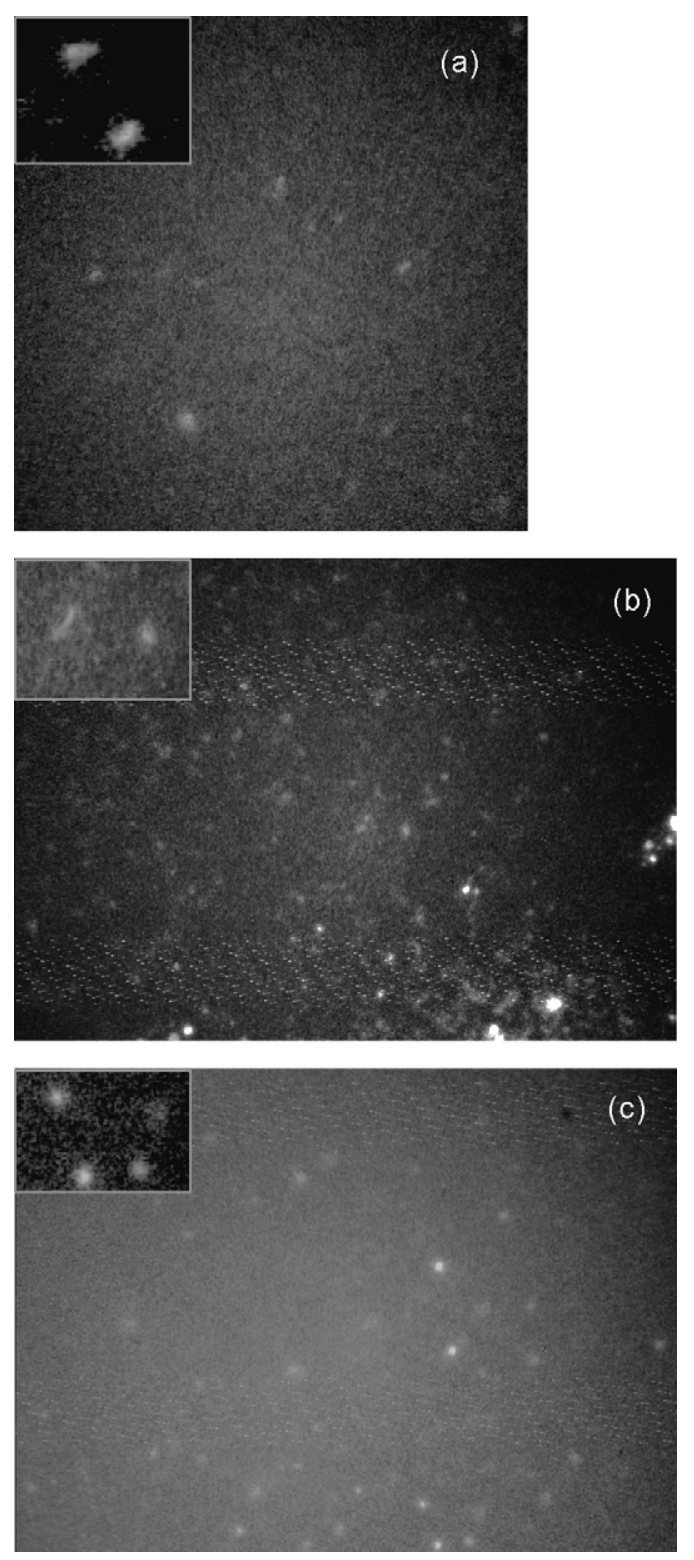

Fig. 3. Typical fluorescence micrographs of T2 DNA in buffer solution at different conformational states as induced by ALA addition: (a) unfolded DNA molecules; (b) coexistence between unfolded and folded; (c) folded DNA molecules. All insets correspond to magnified areas chosen of the correspondent pictures. $T=25^{\circ} \mathrm{C}$.

the inner microstructure changes with $R$. A correlation between the precipitated complexes and the complexes remaining in the supernatant is been presented.

\subsubsection{Characterization of the microstructure of the concentrated phase by SAXS}

In Fig. 4 the SAXS spectra for the precipitate of samples with $R=0.8,1.0,1.2$ and 1.5, as depicted in the image, can be seen. Due to the redissolution effect mentioned above it was difficult to obtain sufficient amount of precipitate to perform SAXS experiments for higher $R$ values than 1.5. For all samples studied a short-range amphiphile lamellar structure (with $q$ values in the ratios 1:2:3) and with an additional 1D DNA arrangement within 


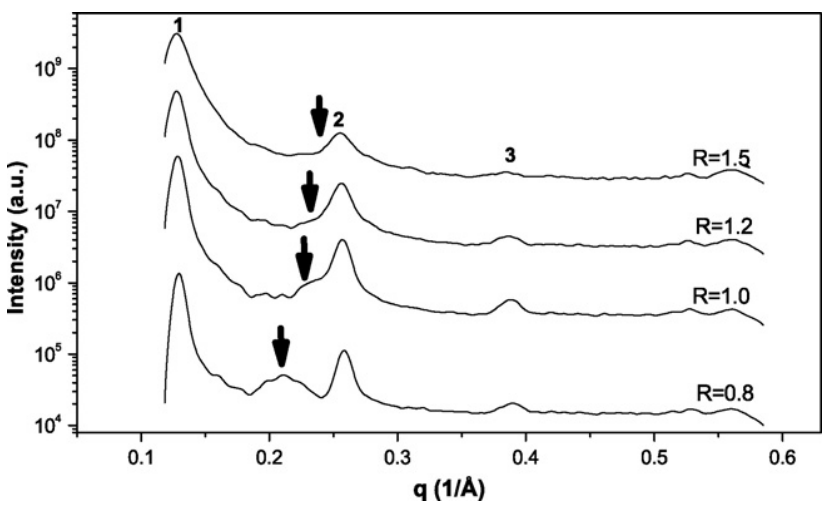

Fig. 4. SAXS diffractograms of precipitated complexes of DNA and catanionic vesicles at different DNA to effective cationic surfactant charge ratios, $R(0.8$, $1.0,1.2,1.5)$, as depicted in the figure. Measurements were performed at both $T=25$ and $37^{\circ} \mathrm{C}$ showing the same results. Here we illustrate the ones performed at $37^{\circ} \mathrm{C}$.

these stacks has been deduced. A repeat distance of $4.7 \mathrm{~nm}$ for the lamellar structure has been calculated for all samples. Correlating this value with the repeat distance of $4.7 \mathrm{~nm}$ obtained from cryo-TEM (see below) for the sample with $R=0.8$, Fig. 8b, one can see a good agreement. The additional organization related to the DNA-DNA correlation is indicated by the arrows in the spectra. For $R=0.8$ we can reliably determine the DNA-DNA spacing as being $28 \mathrm{~nm}$. However, from $R=1.0$ and upwards, the DNA-DNA spacing peak starts to interfere with the second diffraction peak of the surfactant organization, with a partial overlap, making it less defined and broader; this makes it difficult to determine the DNA-DNA spacing. Nevertheless, we can safely state that there are higher $q$ values as the amount of DNA increases, indicating that the DNA molecules, as expected, approach each other.

\subsubsection{Qualitative observations of phase separation}

All mixtures were prepared by adding DNA to the vesicle solutions at different charge ratios, $R$, between DNA and vesicles, from $R$ equal to 0.2 until 2.5. Phase separation occurred for all samples, and increased with $R$ until the isoelectric point $(R=1)$, from which point on partial redissolution of the precipitate starts to take place. For $R$ values below 0.8 , the supernatant presented a turbid bluish look; within $0.8<R<1.2$, a clear solution could be visualized, while for higher $R$ values it became turbid again, but with a more transparent appearance than for lower $R$ values.

Turbidity measurements were performed for the supernatant by measuring the optical absorbance at $350 \mathrm{~nm}$. As can be seen in Fig. 5, the supernatant turbidity decreases with DNA addition and reaches a minimum around charge neutrality, $R=1.0$. This confirms our observations that the maximum in precipitation occurs around $R=1$. Above this value, turbidity starts to increase; within $1.0<R<1.6$ it suffers a small increase and after $R=1.6$ a large one. This increase in turbidity also correlates well with our observation that the amount of precipitate visualized in the samples decreases for higher $R$ values, demonstrating that at this point it starts to be redissolved back into solution. However, only partial redissolution of the precipitate was observed.

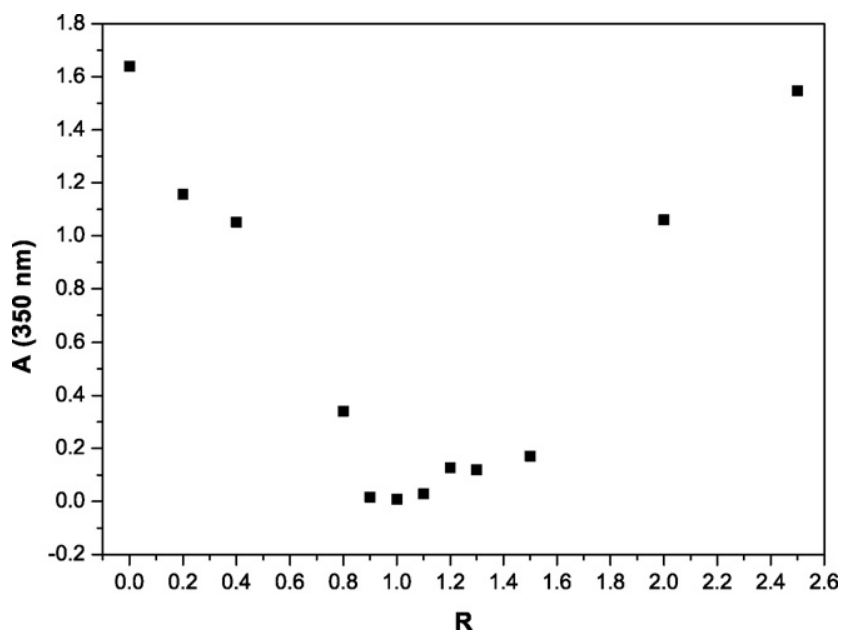

Fig. 5. Turbidity measurements for the supernatant for the mixtures of the ALA/SOS vesicles with DNA as a function of $R, R=[\mathrm{DNA}] /\left[\mathrm{S}^{+}\right]_{\mathrm{eff}}$. Absorbance values were measured at the wavelength of $350 \mathrm{~nm} . R=0$ corresponds to the vesicle sample alone. All samples were measured at $T=25^{\circ} \mathrm{C}$.

\subsubsection{Observations related to the solution complexes}

3.2.3.1. Cryo-TEM. Cryo-TEM was applied to investigate the size, morphology and inner structure of the complexes formed when oppositely charged vesicles interact with DNA. In Table 1 a rough quantification of the fraction of each kind of structures found in the cryomicrographs has been made. In this determination we took into account the vesicle structures as well as the complexes of different size, i.e., below and above $300 \mathrm{~nm} \times 300 \mathrm{~nm}$.

In Figs. 6-13 we provide cryo-TEM micrographs, which are representative of the structures found in the studied samples, for different $R$ values.

For the sample with $R=0.2$ (Fig. 6a and b), as can be seen from Table 1, almost no complexes were visualized; $96 \%$ of the sample was constituted by unperturbed vesicles. However, these vesicles seem already to be rich in DNA since they are beam sensitive. If we allow the electron beam to irradiate the sample for a little less than $1 \mathrm{~min}$ the vesicle structures begin to burn and this has been related before with the presence of DNA [35].

Table 1

Observed fractions of the aggregates visualized by cryo-TEM for all studied $R$ values, $R=[\mathrm{DNA}] /\left[\mathrm{S}^{+}\right]_{\mathrm{eff}}$

\begin{tabular}{llll}
\hline$R$ & $x_{\mathrm{c}<300 \mathrm{~nm} \times 300 \mathrm{~nm}}$ & $x_{\mathrm{c}>300 \mathrm{~nm} \times 300 \mathrm{~nm}}$ & $x_{\mathrm{V}}$ \\
\hline 0.2 & 0.04 & 0 & 0.96 \\
0.4 & 0.80 & 0.13 & 0.07 \\
0.8 & 0.52 & 0.48 & 0 \\
1.0 & 0.24 & 0.76 & 0 \\
1.2 & 0.57 & 0.43 & 0 \\
1.5 & 0.52 & 0.48 & 0 \\
2.0 & 0.90 & 0.10 & 0 \\
2.5 & 0.67 & 0.33 & 0
\end{tabular}

A separation between the fraction of complexes with apparent area size smaller or larger than $300 \mathrm{~nm} \times 300 \mathrm{~nm}$, respectively, $x_{\mathrm{c}<}<300 \mathrm{~nm} \times 300 \mathrm{~nm}$ and

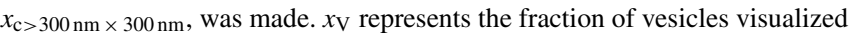



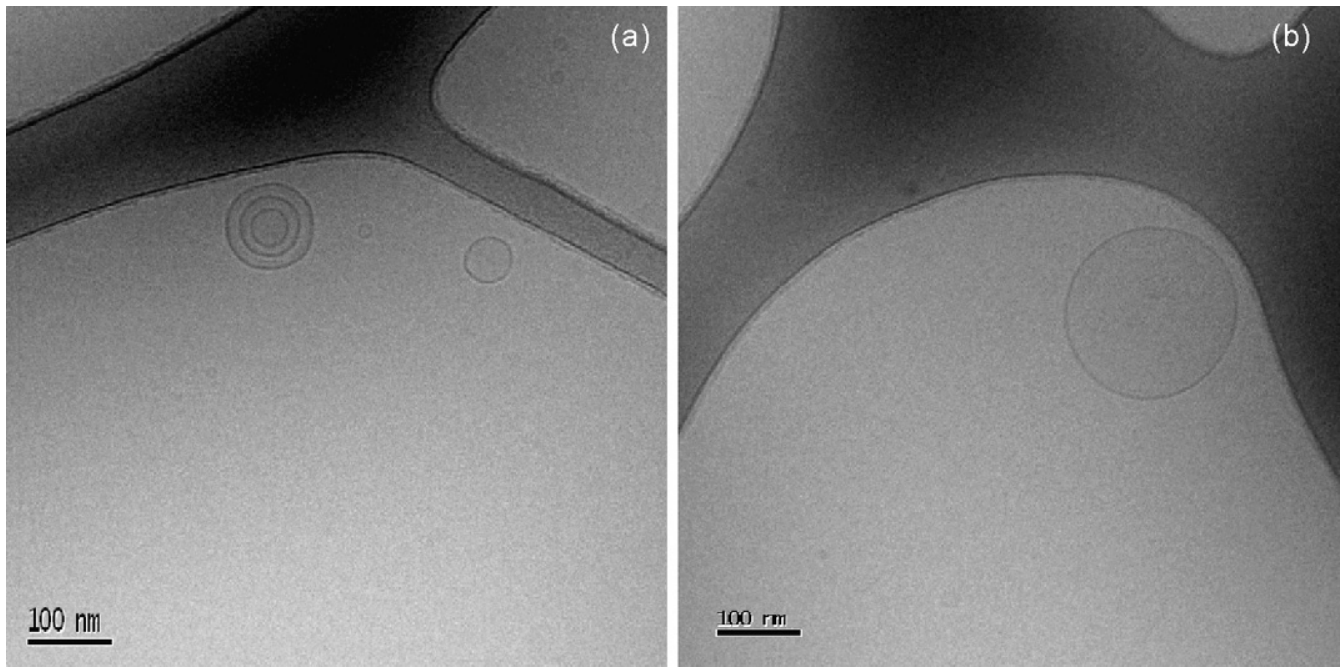

Fig. 6. Cryo-TEM micrographs of the supernatant for the mixture of ALA/SOS vesicles and DNA at $R=0.2 . T=25^{\circ} \mathrm{C}$.

The sample of $R=0.4$ (Fig. 7a-c) shows a fraction of $80 \%$ of particles presenting areas below $300 \mathrm{~nm} \times 300 \mathrm{~nm}$ and some larger particles start to appear. Vesicles were still found and they also seem to be DNA-rich.

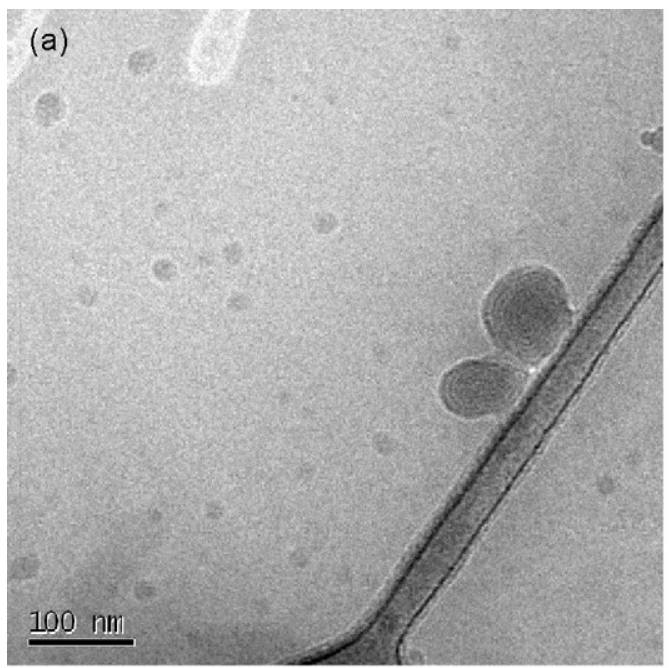

Aggregation between individual complexes becomes evident in the images from sample $R=0.8$ (Fig. 8); consequently, the fraction of larger aggregates increases to $48 \%$. From this sample and onwards no more vesicles are visualized. An expansion of

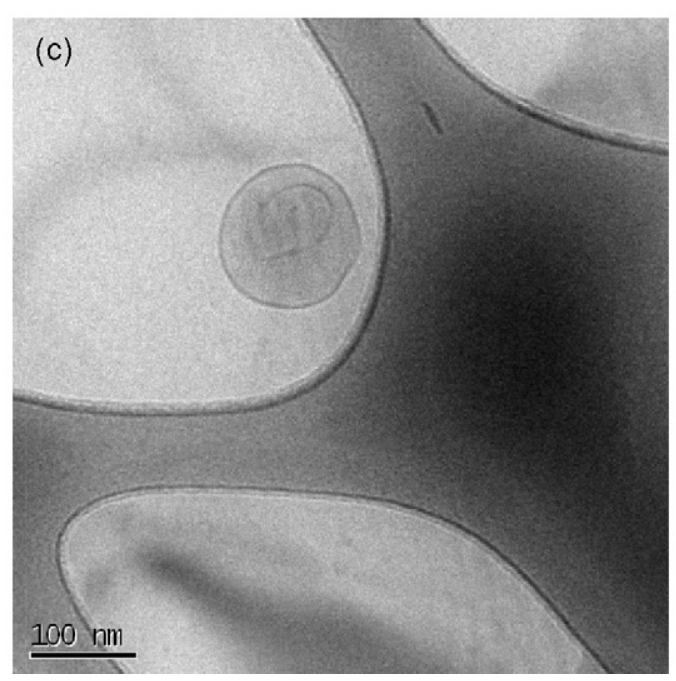

Fig. 7. Cryo-TEM micrographs of the supernatant for the mixture of ALA/SOS vesicles and DNA at $R=0.4 . T=25^{\circ} \mathrm{C}$. 

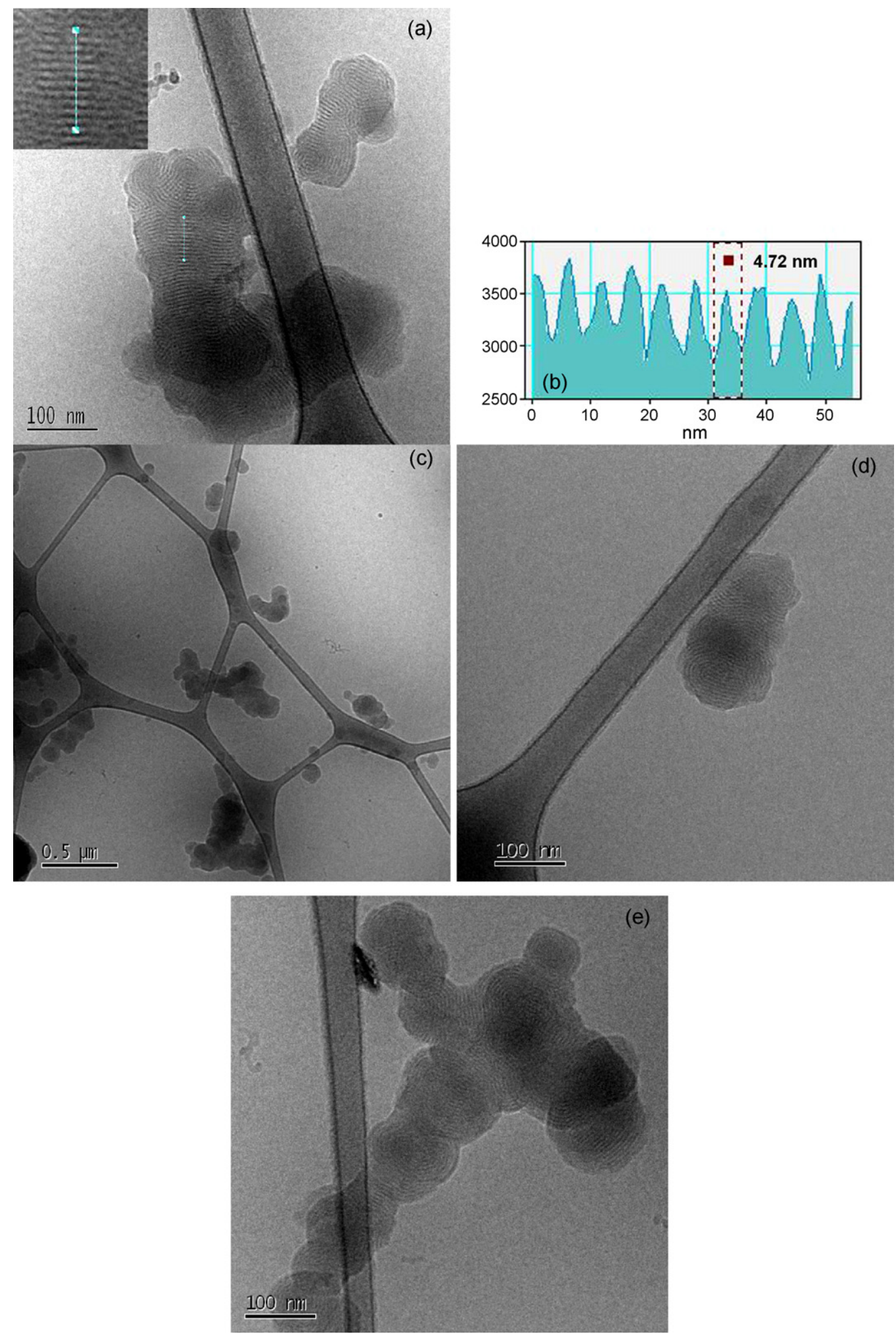

Fig. 8. Cryo-TEM micrographs of the supernatant for the mixture of ALA/SOS vesicles and DNA at $R=0.8$. (a, $\mathrm{c}$, d, and e). A magnified detail of (a) can be seen in the inset of this image; the electron density of the presented line is shown in (b), where a spacing periodicity of $4.72 \mathrm{~nm}$ is shown for the multilamellar structures formed. $T=25^{\circ} \mathrm{C}$. 

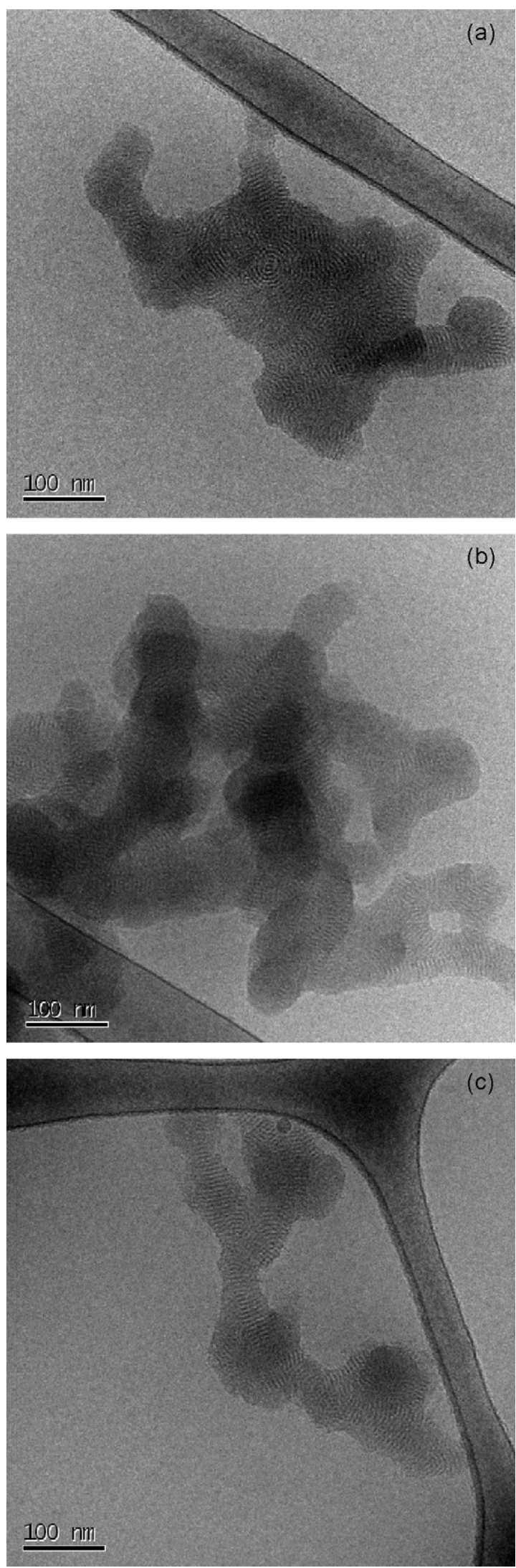

Fig. 9. Cryo-TEM micrographs of the supernatant for the mixture of ALA/SOS vesicles and DNA at $R=1.0 . T=25^{\circ} \mathrm{C}$.
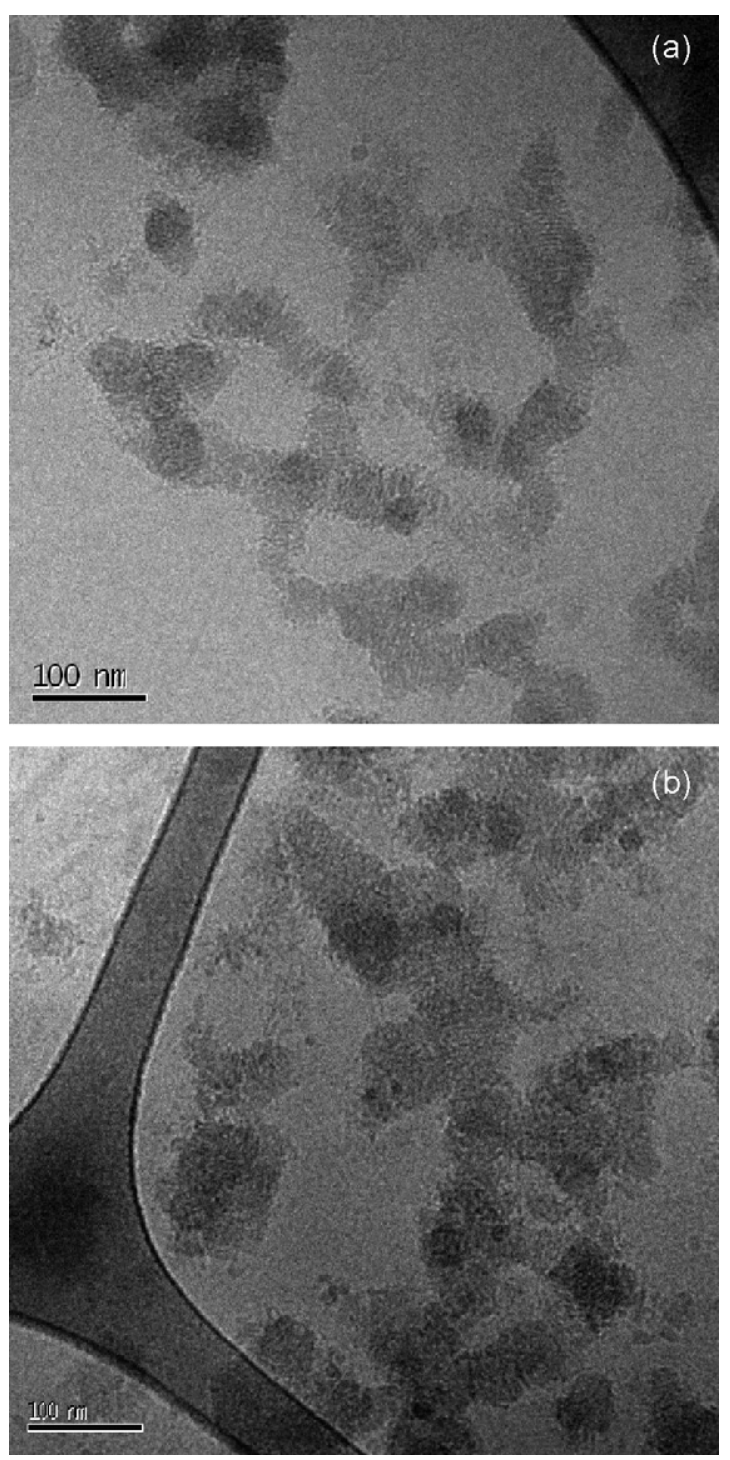

Fig. 10. Cryo-TEM micrographs of the supernatant for the mixture of ALA/SOS vesicles and DNA at $R=1.2 . T=25^{\circ} \mathrm{C}$.

an area in Fig. 8a, where perfectly parallel bilayers can be visualized, is represented as an inset of the same image. In Fig. 8b, the electron density profile of this inset is also represented; perfectly arranged and equally separated minima give us a bilayer distance of $4.7 \mathrm{~nm}$.

At $R=1.0$, Fig. 9a-c, aggregation is at its maximum with the fraction of larger complexes reaching a value of $76 \%$. A reorganization of the inner bilayers through merging is evident throughout the cryomicrographs.

Above the charge equivalence, for $R=1.2$, Fig. 10a and $\mathrm{b}$, the system has an excess of negative charges giving rise to a swelling effect due to electrostatic repulsion and the fraction of larger aggregates decreases, while the fraction of smaller aggregates increases. The same is observed for sample $R=1.5$, Fig. $11 \mathrm{a}-\mathrm{c}$, presenting more or less the same features. However, for $R=2.0$, Fig. 12a and b, the total number of visualized larger aggregates decreases considerably, the smaller complexes being again the most preferred ones. 

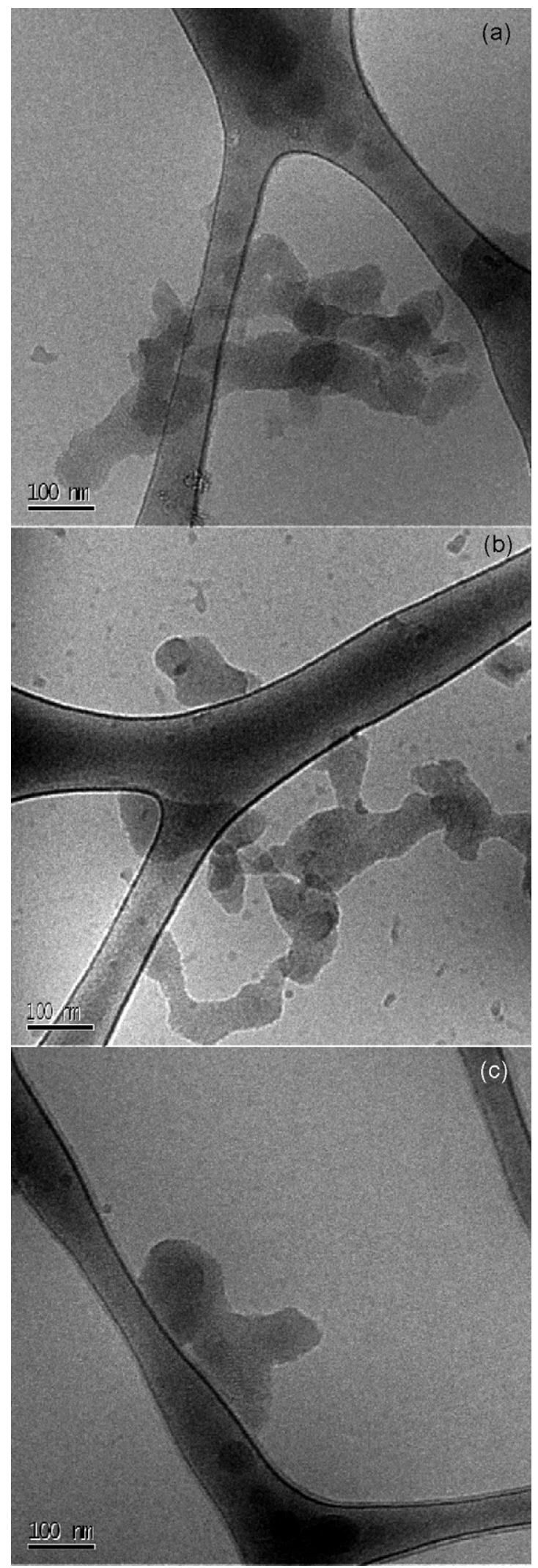

Fig. 11. Cryo-TEM micrographs of the supernatant for the mixture of ALA/SOS vesicles and DNA at $R=1.5 . T=25^{\circ} \mathrm{C}$.
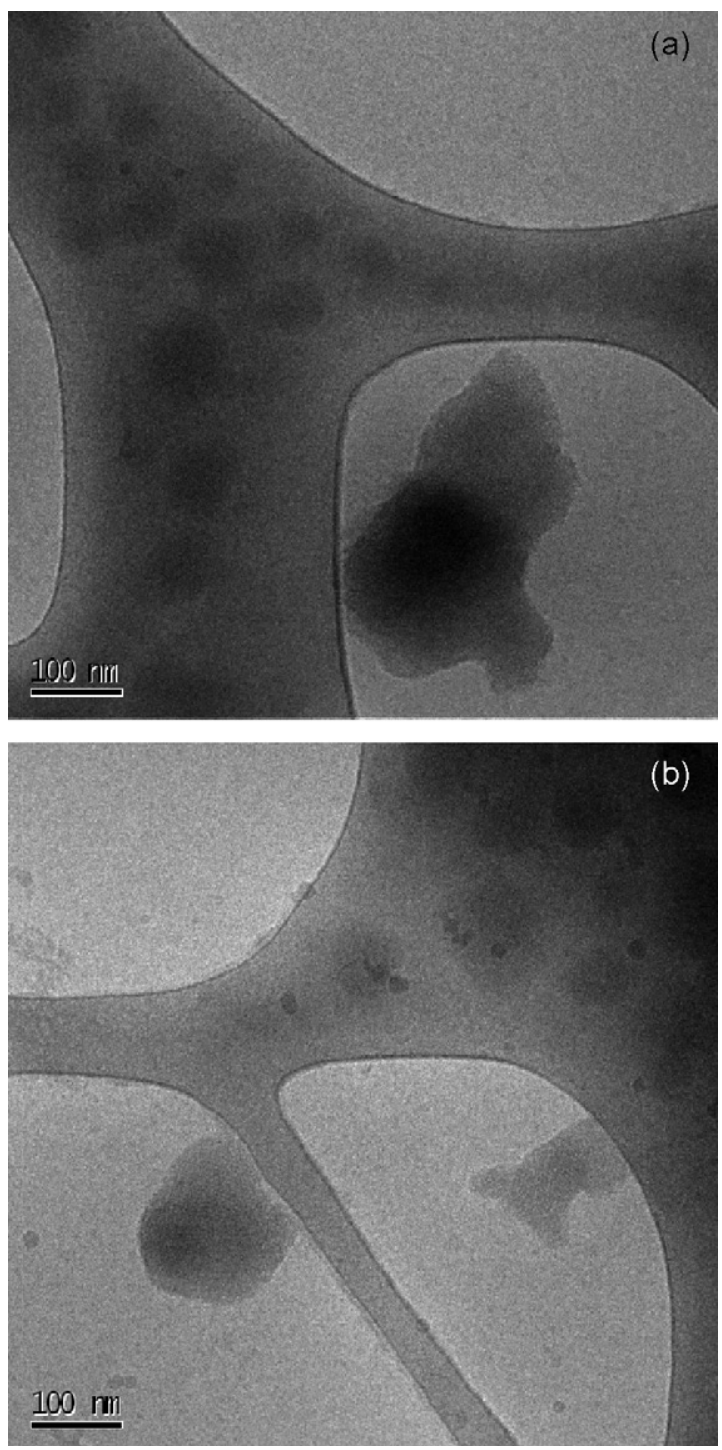

Fig. 12. Cryo-TEM micrographs of the supernatant for the mixture of ALA/SOS vesicles and DNA at $R=2.0 . T=25^{\circ} \mathrm{C}$.

Adding even more DNA into the vesicle solutions, for $R=2.5$, Fig. 13a-c, the number of larger aggregates seen in solution decreases and smaller complexes appear to be the dominant ones. In the inset of Fig. 13c one can visualize the reflections characteristic of a hexagonal array obtained through a fast Fourier transform (FFT) [36] to an area of Fig. 13. The observation of a hexagonal structure for higher $R$ values is interesting although not unexpected from a geometrical point of view, as will be discussed later in Section 4.

It is important to note that by changing the charge ratio between DNA and the catanionic vesicles we are able to control the internal structure, the morphology and the size of the aggregates formed. Initially, for samples with lower DNA content, we see from the cryo-TEM images that small globular complexes (Fig. $7 \mathrm{a}$ and b) are more common, and their inner structure is lamellar. By adding more DNA these individual globular complexes aggregate leading to a morphologically different complex (Fig. 8e). Almost no rearrangement or merging between the individual globular complexes is seen and the size 

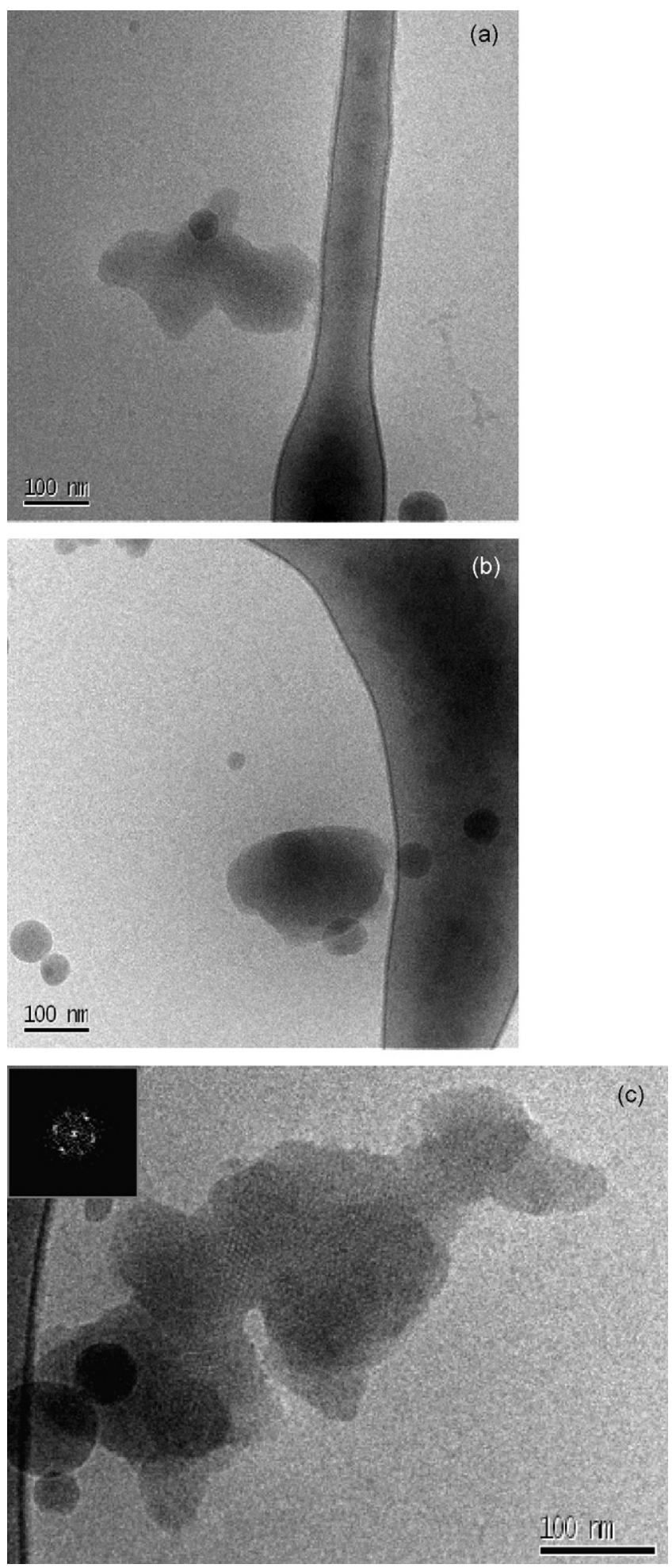

Fig. 13. Cryo-TEM micrographs of the supernatant for the mixture of ALA/SOS vesicles and DNA at $R=2.5$. A fast Fourier transform of an area of the micrograph (c) can be seen in its inset; it indicates the existence of a hexagonal structure. $T=25^{\circ} \mathrm{C}$.

of the aggregates increases greatly. At the isoelectric point, $R=1$, the individual globular complexes seem to have merged into each other by rearranging and reorienting their inner bilayers; as a result we no longer see the individual complexes that form the particle (Fig. 9a). Above this ratio between DNA and the catanionic vesicles, the complexes seem to gradually lose their internal organization and become smaller (Figs. 10-12). Above the isoelectric point between DNA and ALA a completely different internal structure was visualized, a hexagonal one (Fig. 13c).

3.2.3.2. ${ }^{1} H$ NMR. In order to further characterize the phase separation in the mixed catanionic vesicle-DNA solutions at different $R$ values, proton NMR studies were performed. Proton NMR provides information on the hydrogens electronic environment, and the integration of its peaks provides insight regarding the relative numbers of chemically distinct hydrogens within a sample, thus serving as an analytical tool. Additionally, this technique provides limited insight into aggregates present, based on a line broadening effect related to the size of the aggregates formed and to their asymmetry [32,33]. In Fig. 14 are displayed the proton NMR spectra of simple and mixed solutions, SOS alone, ALA alone, vesicles alone, DNA alone, and all the mixtures from $R=0.2$ till 2.5. From a comparison of the different spectra, we can infer that for a mixed solution of all components, at $R=0.2$, only ALA can be traced, from following its peak at around $3.15 \mathrm{ppm}$; this peak will be referred to as the ALA peak in the subsequent text. However, through a fitting procedure we were able to also trace SOS in solution. This fitting procedure works as follows: by following the intensity of the ALA peak and the intensity of the peaks corresponding to the tails (from 0.6 to $2.2 \mathrm{ppm}$ ) as a function of ALA concentration, in samples with ALA alone, we are able to get a fitting curve from which we get the concentration of ALA in the supernatant and we are also able to extrapolate the contribution of ALA to the intensity of the tail peaks in the mixture; moreover, by following the intensity of the peaks corresponding to the SOS tails (from 0.6 to $2.2 \mathrm{ppm}$ ) with the concentration of SOS, in samples with SOS alone, we can get a fitting curve for this surfactant; finally, by subtracting from the total intensity of the tail peaks in the mixtures at different $R$ the contribution of ALA to that peak, we obtain an approximate concentration of SOS in the supernatant. The results of this fitting can be seen in Table 2. In the second column we have the concentration of DNA added to the vesicles for each $R$; in the column denoted as supernatant we have the concentrations of both surfactants in the supernatant obtained from the fitting described; regarding the precipitate column, we take into account that the initial concentration of ALA and SOS in the vesicles was 2.91 and $1.72 \mathrm{mM}$, respectively, and made the assumption that whatever is missing in the supernatant should be in the precipitate, thus the presented values correspond to the difference between the initial concentrations of each surfactant and the ones obtained from the NMR fitting. For higher $R(R>1.5)$ values, the SOS concentration is not presented in Table 2, because a contribution from DNA in solution interferes with peak used for the analysis.

As can be observed, already for $R=0.2$, the ALA concentration in the supernatant decreases and it keeps on decreasing until $R=1.2$; the same can be observed for SOS. However, for further increase of the DNA content, an increase of both surfactant concentrations is observed in the supernatant. 

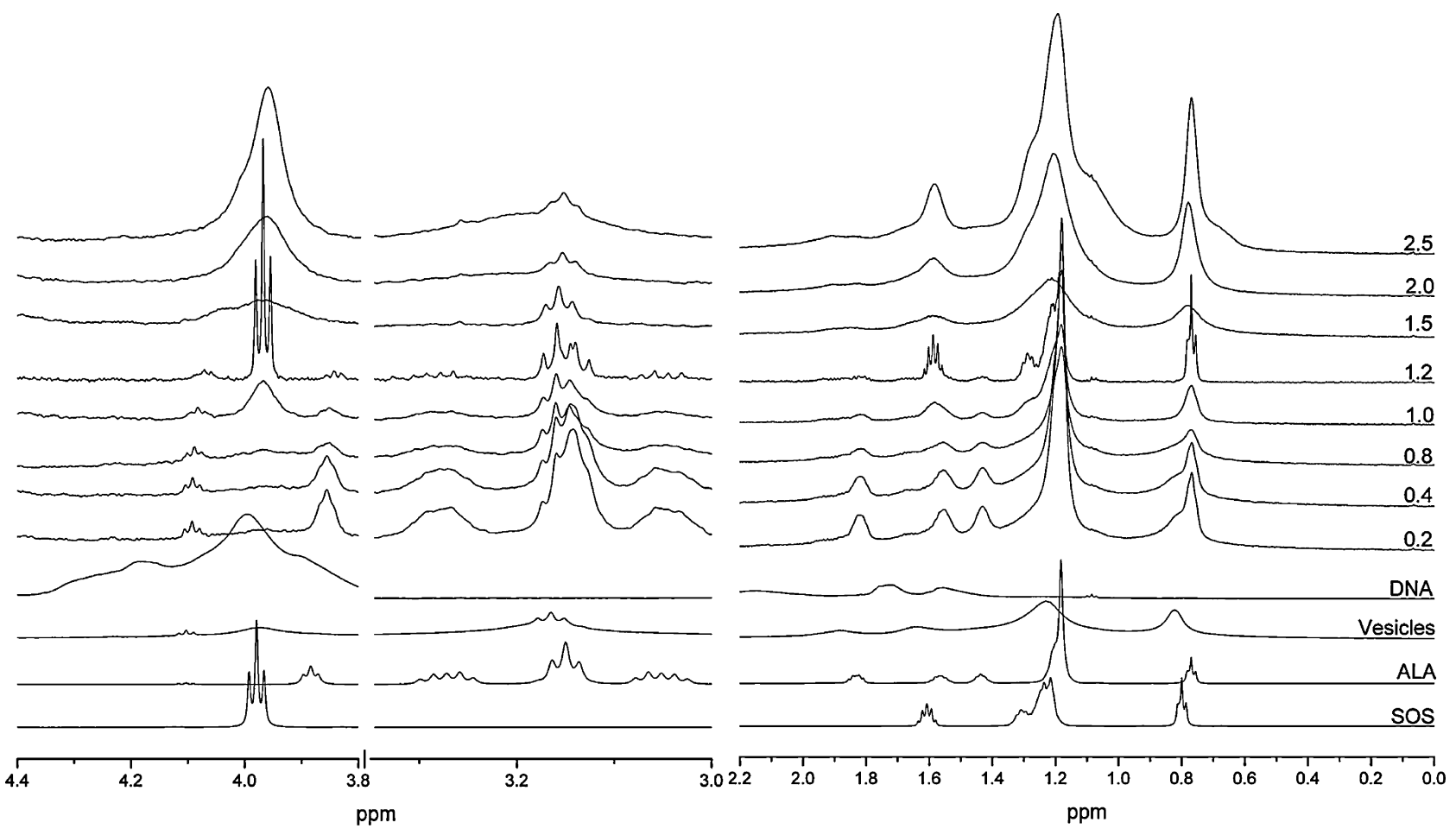

Fig. 14. ${ }^{1} \mathrm{H}$ NMR spectra of solutions of SOS alone, of ALA alone, of catanionic ALA/SOS vesicles, of DNA alone and of the supernatants of the mixed solutions of the vesicles with DNA at different DNA to effective cationic surfactant net charge ratios, $R$, from 0.2 till 2.5 , as depicted in the plots. $T=25^{\circ} \mathrm{C}$.

A closer look at the NMR spectra, see Fig. 14, allow some interesting observations on the association. ALA is always seen in the supernatant, although its peaks, within 3-3.4 ppm, become very broad in the mixture, and lose some intensity, and above a ratio of 1.2 lose some resolution. As for SOS, at the ratio of 0.8 a very subtle bump arises at $4 \mathrm{ppm}$, which becomes more intense at the ratio of 1.0; this increase of intensity can be also attributed to the presence of DNA due to its broad peak, seen in the DNA

Table 2

Experimental and calculated concentrations of the individual components of the mixtures of ALA/SOS vesicles and DNA at different $R$

\begin{tabular}{|c|c|c|c|c|c|}
\hline \multirow[t]{3}{*}{$R$} & \multicolumn{5}{|l|}{ Sample } \\
\hline & \multirow[t]{2}{*}{ [DNA] added } & \multicolumn{2}{|c|}{ Supernatant } & \multicolumn{2}{|c|}{ Precipitate } \\
\hline & & [ALA] & [SOS] & {$[\mathrm{ALA}]^{\mathrm{a}}$} & {$[\mathrm{SOS}]^{\mathrm{b}}$} \\
\hline 0.2 & 0.24 & 1.92 & 1.02 & 0.99 & 0.70 \\
\hline 0.4 & 0.48 & 1.70 & 1.04 & 1.21 & 0.68 \\
\hline 0.8 & 0.95 & 1.17 & 0.79 & 1.74 & 0.93 \\
\hline 1.0 & 1.19 & 0.76 & 0.49 & 2.15 & 1.23 \\
\hline 1.2 & 1.42 & 0.47 & 0.47 & 2.44 & 1.25 \\
\hline 1.5 & 1.78 & 0.80 & 1.11 & 2.11 & 0.61 \\
\hline 2.0 & 2.38 & 1.04 & - & 1.87 & - \\
\hline 2.5 & 2.97 & 1.61 & - & 1.30 & - \\
\hline
\end{tabular}

The column denoted [DNA] added corresponds to the actual DNA concentration added to the sample for each mixture. The columns denoted supernatant give the concentrations of ALA and SOS in the supernatant as obtained from the

${ }^{1} \mathrm{H}$ NMR results through the fitting method explained in the text. The values in the columns denoted precipitate correspond to the precipitate composition as obtained by subtracting from the total concentrations of ALA $(2.91 \mathrm{mM})$ and SOS $(1.72 \mathrm{mM})$ their concentrations in the supernatant.

${ }^{\mathrm{a}}[\mathrm{ALA}]_{\text {precipitate }}=2.91-[\mathrm{ALA}]_{\text {supernatant }}$.

${ }^{\mathrm{b}}[\mathrm{SOS}]_{\text {precipitate }}=1.72-[\mathrm{SOS}]_{\text {supernatant }}$. spectra alone, within 3.9 and $4.1 \mathrm{ppm}$. Line broadening of surfactant peaks is strongly related to the size of aggregates and to their asymmetry and thus provides information on self-assembly structures present [32,33]. For $R=1.2$, it becomes clear that only SOS contributes to this peak; furthermore, the whole spectrum presents similarities with the spectrum of SOS alone, although ALA features continue to be seen, even though less markedly. As we move up in the stacked spectra, we can observe that this peak at around $4 \mathrm{ppm}$ becomes again broad, meaning that it becomes again part of a larger self-assembly structure, most probably somewhat anisometric micelles. Taking into consideration that the isoelectric point for the mixture of DNA and ALA alone is reached at a ratio $R$ of around 2.45, the probability of DNA to be found free in the bulk above this ratio is significant; this can be noticed from several features of the DNA spectra, seen on the spectra for $R=2.5$, like: the appearance of a right shoulder on the methylene peak (around $1.1 \mathrm{ppm}$ ); and, the pronounced increase of the intensity of the peak at $4 \mathrm{ppm}$, which also presents a very subtle shoulder at its left, probably related with the overlap between the SOS and DNA peaks.

\section{Discussion}

\subsection{Compaction of DNA by an amino acid-based surfactant}

Interactions between polyelectrolytes and oppositely charged amphiphiles lead to the formation of a complex, in which the amphiphile binds to the polyelectrolyte through a strong electrostatic attraction driven by the translational entropy of 
counterions, magnified by polymer-induced surfactant selfassembly [37,38]; concomitant to this there are smaller or larger conformational changes in the polyelectrolyte chains. These interactions are known to be highly cooperative [12,39]. However, DNA presents some different features in the binding mechanism, which need our consideration in this discussion. Native DNA is a highly charged polymer; thus it is a very stiff polyanion. Due to its high linear charge density, it interacts quite strongly with cationic surfactants; thus quite low surfactant concentrations are needed for conformational changes to occur. The existence of a region where coils coexist with globules lead us to believe in a distinctly different binding mechanism for DNA [14] than for other polyelectrolytes: as binding starts to take place at one DNA strand, further binding to that same strand is facilitated leading to saturation before binding to another DNA strand starts.

In Fig. 2 we represent together with our results for ALA and DNA the results of FM studies performed by Dias et al. [14], where the conformational changes of DNA chains were followed on the addition of classical cationic surfactants, alkyl trimethylammonium bromides, with $\mathrm{C}_{12}, \mathrm{C}_{14}$ and $\mathrm{C}_{16}$ chains, DTAB, TTAB and CTAB, respectively. Comparing these results with the ones we present for ALA can help us to understand some features of these interactions. One can see that for ALA and DTAB, both with the same tail length, ALA is more efficient in compacting DNA, probably due to its double charge. However, comparing with the surfactant with longer tail, CTAB, the trend seems to be the opposite, the surfactant with longer tail, CTAB, being the most efficient in compaction. When comparing ALA and CTAB we are encountering the influences of both charge and hydrophobicity. From Fig. 2 one can infer that regarding the initial interaction with DNA the behavior of the two surfactants does not differ much; however, CTAB is more efficient in compacting all DNA molecules as represented by the small range of coexistence. Thus, ALA appears to show a higher cooperativity in relation to the strength of interaction. One might infer that both surfactants interact with DNA at quite low, and approximately equal surfactant concentrations, but as the concentration increases CTAB becomes more efficient in saturating all polymer coils. Furthermore, if we consider the CMC of the different surfactants considered, we notice that it decreases in the following order: from DTAB (15.6 mM), TTAB (4.4 mM), ALA $(1.8 \mathrm{mM})$ and CTAB $(0.92 \mathrm{mM})$, which coincides with the compaction efficiency. Thus, surfactants that easily form micelles (lower CMC) are generally more efficient in compacting DNA.

It is interesting to note that the onset of compaction with ALA occurs at a lower concentration than expected from its $\mathrm{CMC}$, and the cooperativity is higher. We can only attribute this to the divalent character of this surfactant.

The discussion below will concern DNA systems containing both a cationic and an anionic surfactant. It is, therefore, relevant to point out that addition of anionic surfactant to a cationic surfactant-DNA solution, with DNA in the compacted state, may lead to unfolding of DNA. Dias et al. have shown that unfolding of previously compacted DNA molecules in the presence of an anionic surfactant, sodium cetyl sulfate, SCS, was independent of the hydrophobicity of the initial compact- ing agent for all systems [9], thus, showing the role of mixed aggregate formation. Thus, it could be deduced from this study of decompaction that the interaction between the oppositely charged surfactants is stronger than between the cationic surfactant and DNA.

\subsection{Interaction between DNA and catanionic vesicles}

\subsubsection{Microstructure of the DNA-vesicle complexes}

As mentioned above, when performing SAXS measurements on the precipitated complexes at different $R$ values we obtained spectra characteristic of a lamellar structure with an additional diffraction peak from the DNA arrangement within the lamellar stacks. The described structure presents a repeat distance of $4.7 \mathrm{~nm}$ and a DNA-DNA spacing, which decreases as more DNA is added. This can be interpreted in terms of an increasing introduction of DNA into the lamellar phase. This is compensated by a release of the anionic surfactant; the bilayers, therefore, become increasingly positively charged and compensate for the increased DNA concentration in the water layers of the lamellar phase. The formation of this kind of structure has previously been reported in the literature for lipidic and amphiphilic-based systems and DNA [8,40-42]. Furthermore, we believe that the fact that the DNA-DNA spacing decreases for $R$ values above 1 is characteristic of catanionic-based systems, and that it represents an advantage from a transfection point of view [43] since it allows further compaction of DNA compared with liposome-based systems, where, after reaching the charge stoichiometry between cationic lipid and DNA, further addition of DNA does not result in a decrease in the DNA-DNA spacing within the complex [44].

What can be inferred from a repeat distance of $4.7 \mathrm{~nm}$, as obtained from both SAXS and cryo-TEM studies? In a rough estimate, we consider the maximum length of a fully extended alkyl chain to be given in nanometers $(\mathrm{nm})$ by the equation $l=0.15+0.127 n_{\mathrm{c}}$, where $n_{\mathrm{c}}$ is the number of carbon atoms in the chain [38]. Here we have a mixture of two surfactants one with 12 and one with 8 carbons in the alkyl chains; we would have $l_{\mathrm{ALA}}=1.67 \mathrm{~nm}$ and $l_{\mathrm{SOS}}=1.17 \mathrm{~nm}$. From the literature we know that in the liquid state the membrane thickness is approximately $1.6 l_{\max }$. Since the bilayer membrane is constituted by both surfactants we would have an intermediate membrane thickness; while the mean is $d_{\text {mem }}=1.6\left(l_{\mathrm{ALA}}+l_{\mathrm{SOS}}\right) / 2=2.27 \mathrm{~nm}$ we would expect a somewhat higher value since the surfactant with longer alkyl chain would be the one mainly determining the thickness. A DNA molecule with one hydration shell has a diameter of ca. $2.5 \mathrm{~nm}$. Adding this to the bilayer thickness we get a repeat distance of approximately $4.77 \mathrm{~nm}$ or slightly above, which agrees well with the experimental values obtained from both cryo-TEM and SAXS. These results indicate that both amphiphiles are contributing to the final bilayer thickness, which is quite constant in the range of $0.8<R<1.5$, in spite of the indication of some changes in the bilayer composition (Table 2).

As mentioned above, we observed an indication of the presence of a hexagonal diffraction pattern, obtained from a FFT made to a complex visualized by cryo-TEM, for the sample at $R=2.5$. Hexagonal liquid crystalline packing in 
DNA-amphiphile systems has previous been documented for very different cases. The hexagonal phase can be either of the normal type, with hexagonally packed amphiphile rod-like aggregates in a water continuum, or of the reversed type with hexagonally packed rod-shaped reversed micelles, surrounding the DNA chains, in a continuum of the nonpolar parts. In our studies, SAXS does not provide an unambiguous distinction between hexagonal phases; only with more diffraction peaks and better information on the relative peak intensities could inverse and normal hexagonal structures be distinguished. However, it has been possible by arguments of packing to identify either normal or reversed phases. When DNA associates with simple or mixed lipids or amphiphiles that are relatively nonpolar, the hexagonal phase could be identified as the reversed one $[40,42,45]$. On the other hand, Leal et al. could demonstrate that for the case of the interaction of DNA with a single chained cationic surfactant, CTAB, the isoelectric complex presented a normal hexagonal structure as for CTAB alone [46,47]. In the study of the phase behavior of a 12 carbon chain cationic surfactant in water, Balmbra et al. found the following liquid crystalline phase sequence at room temperature: micellar (micellar) cubic, hexagonal (bicontinuous) cubic and lamellar [48], which agrees well with the accepted Fontell scheme [49] for the dependence of surfactant liquid crystal structure on composition. Taking these previous observations into account and relating them with the indications of our experiments we can infer that the hexagonal structure observed by us must be of the normal type. Thus, at the ratio $R$ of 2.5 we are above the point of charge stoichiometry between ALA and DNA and SOS would be extensively released from the complex. A great extent of SOS release from the complexes into the bulk solution was indeed indicated by the increase of the intensity of the proton NMR peak around $4 \mathrm{ppm}$. There is thus a strong indication that we are dealing with a complex containing only ALA and DNA and an evidence of a phase transition from lamellar to hexagonal when expelling SOS from the bilayer.

\subsubsection{Remarks on the phase behavior}

The interaction between oppositely charged surfactants and DNA is strongly attractive. In our study we observed precipitation over all mixing ratios, which correlate well with a strong association. As the concentration of DNA increases in the vesicle solution, the amount of precipitate increases till we reach charge neutrality $(R=1)$, where we observed a minimum in turbidity of the supernatant; from this point on, as more polyelectrolyte is added into solution, redissolution of the precipitate starts, as noted also by an increase in the turbidity of the supernatant. These features are commonly associated with polyelectrolyte-oppositely charged surfactant systems [50-52], as well as oppositely charged mixed polyelectrolyte-systems [53]. In addition, Skepö et al. demonstrated, by means of Monte Carlo simulations, that at macromolecular charge equivalence, the system becomes unstable and phase separates; moreover, in excess of polyelectrolyte, a redissolution occurs, resulting in a single and stable macroion-polyelectrolyte solution [54]. In a study of the system tetradecyltrimethylammonium bromide/sodium polyacrylate/water, on the addition of excess of polyelectrolyte, Carnali observed complete redissolution of the precipitate; by adding even more polyelectrolyte, another phase separation occurred, this time of the segregative type [52]. This behavior is not observed in the case of DNA in the presence of oppositely charged catanionic vesicles as demonstrated by Dias et al.; as in the present study, complete redissolution of the precipitate on the addition of excess of DNA to the vesicle system was not observed [8].

In general we can infer that the introduction of an amino acid-based surfactant in the catanionic system, does not give rise to qualitative differences in the phase behavior of mixed DNA-surfactant systems as compared to classical surfactants [8].

\subsubsection{Structure of the solution complexes}

Cryo-TEM images together with the calculated fractions of different complexes, shown in Table 1, seem to give a clear picture of the association in the supernatant solution. As DNA is added to the vesicle solution, small complexes start to form at low concentrations; at slightly higher DNA concentrations they begin to aggregate forming larger clusters, as noted from

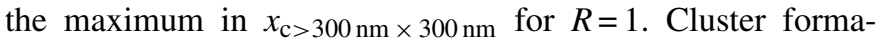
tion at electroneutrality has been seen previously in systems of hydrophobically modified polyelectrolytes/oppositely charged surfactants [53], on DNA/cationic liposomes [8,44,55,56] as well as in Monte Carlo simulations of polyelectrolyte-macroion solutions [54]. Above this isoelectric point, the clusters start to become smaller and the complexes begin drifting apart from each other, due to electrostatic repulsions generated by the excess of negative charges in the structures. Rädler et al. have also described this decrease in aggregation and related it with the charge reversal of the complexes due to excess of DNA [44]. From this point on, the fraction of smaller complexes increases considerably and the amount of complexes visualized decreases. In a study on DNA in the presence of oppositely charged catanionic vesicles it was demonstrated that excess of DNA did not lead to the coexistence of DNA-vesicle complexes and DNA [44], but most probably to the inclusion of DNA in excess in the complexes and, therefore, to a coexistence of complexes and anionic surfactant micelles expelled from the bilayers [8]. Additional information comes from our proton NMR results (Fig. 14), more specifically from the change in the SOS peaks at $4 \mathrm{ppm}$ for the spectra at a ratio $R=1.2$, which becomes very well resolved and similar to the peaks of SOS alone in solution; this we interpret in terms of a release of SOS from the bilayers. The fact that for higher $R$ values this same peak becomes broad corroborates the possible formation of micelles. This broadening suggests anisometric micelles. While SOS alone would only form spherical micelles, the presence of ALA in the micelles will change surfactant packing and induce a departure from a spherical shape. When DNA and SOS segregate into different complexes ALA will be distributed between them; as argued above the ALA-SOS interaction is expected to be stronger than that between ALA and DNA.

Above the charge equivalence between ALA and DNA, the excess DNA is thus believed to be free in solution coexisting with the SOS micelles and the few ALA/DNA hexagonal complexes 
found. This is based on the fact that the features of the DNA NMR spectra alone start to be noticed for $R=2.5$ by the right shoulder on the methylene peak together with the pronounced increase of the peak at $4 \mathrm{ppm}$, which also presents a subtle shoulder to its left. The likely possibility of the existence of mixed ALA/SOS micelles coexisting in solution cannot be directly proved but is, as indicated above, suggested by the broadening of the SOS peak.

\section{Conclusions}

In this study we showed by FM how an amino acid-based cationic surfactant, ALA, is able to compact DNA on a single molecular level. As already mentioned in the literature, the coexistence region with both unfolded and folded DNA conformations is due to a facilitated binding to one DNA helix after the first surfactant molecules bind to it. This we have previously referred to as a double cooperativity.

The interaction between positively charged amino acid-based catanionic vesicles is, as expected, strongly associative. Mixing DNA and vesicles in solution leads to phase separation for all mixing ratios between DNA and catanionic surfactant studied; above the isoelectric point, partial redissolution of the complexes is observed. The inner structure of the precipitate corresponds to organization in bilayers of both surfactants, while DNA occupies the interbilayer gap. DNA molecules located within these lamellar stacks present a characteristic spacing which decreases on further DNA addition. In the supernatant, as the DNA content increases, the individual complexes start to aggregate forming large clusters; above the isoelectric point, due to an excess of negative charges, the clusters disintegrate and the complexes become smaller; at this point, SOS starts to be released from the bilayers and a complex formed by ALA and DNA appears, which has a hexagonal inner structure. SOS is believed to selfassemble into micelles and coexist in solution with the excess DNA and the hexagonal ALA/DNA complex.

\section{Acknowledgments}

We are grateful to Gunnel Karlsson for aid in cryo-TEM instrumentation. This work was supported by grants from the Fundação para a Ciência e Tecnologia (FCT, project POCTI SFRH/BD/8357/2002), the Swedish Research Council (VR), the Spanish CYCIT (reference PPQ2003-01834), and a grant from an EU Research Training Network, CIPSNAC (contract number: MRTN-CT-2003-504932).

\section{References}

[1] A.S. Ulrich, Biophysical aspects of using liposomes as delivery vehicles, Biosci. Rep. 22 (2) (2002) 129-150.

[2] E.W. Kaler, et al., Spontaneous vesicle formation in aqueous mixtures of single-tailed surfactants, Science 245 (4924) (1989) 1371-1374.

[3] E.W. Kaler, et al., Phase-behavior and structures of mixtures of anionic and cationic surfactants, J. Phys. Chem. 96 (16) (1992) 6698-6707.

[4] E.F. Marques, et al., Vesicle formation and general phase behavior in the catanionic mixture SDS-DDAB-water. The anionic-rich side, J. Phys. Chem. B 102 (35) (1998) 6746-6758.
[5] E.F. Marques, et al., Vesicle formation and general phase behavior in the catanionic mixture SDS-DDAB-water. The cationic-rich side, J. Phys. Chem. B 103 (39) (1999) 8353-8363.

[6] D.D. Lasic, et al., Spontaneous vesiculation, Adv. Colloid Interface Sci. 89 (2001) 337-349.

[7] S.M. Mel'nikov, et al., DNA conformational dynamics in the presence of catanionic mixtures, FEBS Lett. 453 (1-2) (1999) 113-118.

[8] R.S. Dias, B. Lindman, M.G. Miguel, DNA interaction with catanionic vesicles, J. Phys. Chem. B 106 (48) (2002) 12600-12607.

[9] R.S. Dias, B. Lindman, M.G. Miguel, Compaction and decompaction of DNA in the presence of catanionic amphiphile mixtures, J. Phys. Chem. B 106 (48) (2002) 12608-12612.

[10] K. Wagner, et al., Direct evidence for counterion release upon cationic lipid-DNA condensation, Langmuir 16 (2) (2000) 303-306.

[11] S.M. Melnikov, V.G. Sergeyev, K. Yoshikawa, Discrete coil-globule transition of large DNA induced by cationic surfactant, J. Am. Chem. Soc. 117 (9) (1995) 2401-2408.

[12] S.M. Melnikov, V.G. Sergeyev, K. Yoshikawa, Transition of doublestranded DNA chains between random coil and compact globule states induced by cooperative binding of cationic surfactant, J. Am. Chem. Soc. 117 (40) (1995) 9951-9956.

[13] S.M. Melnikov, et al., Cooperativity or phase transition? Unfolding transition of DNA cationic surfactant complex, J. Chem. Phys. 107 (17) (1997) 6917-6924.

[14] R.S. Dias, B. Lindman, M.G. Miguel, Interactions between DNA and surfactants, Progr. Colloid Polym. Sci. (2001) 163.

[15] Y.S. Me"nikova, B. Lindman, pH-controlled DNA condensation in the presence of dodecyldimethylamine oxide, Langmuir 16 (14) (2000) 5871-5878.

[16] L. Karlsson, M.C.P. van Eijk, O. Soderman, Compaction of DNA by gemini surfactants: effects of surfactant architecture, J. Colloid Interface Sci. (2002) 290-296.

[17] Y. Ichiba, K. Yoshikawa, Single chain observation on collapse transition in giant DNA induced by negatively-charged polymer, Biochem. Biophys. Res. Commun. 242 (2) (1998) 441-445.

[18] K. Yoshikawa, Y. Yoshikawa, T. Kanbe, All-or-none folding transition in giant mammalian DNA, Chem. Phys. Lett. 354 (3-4) (2002) 354-359.

[19] S. Kidoaki, K. Yoshikawa, Folding and unfolding of a giant duplex-DNA in a mixed solution with polycations, polyanions and crowding neutral polymers, Biophys. Chem. 76 (2) (1999) 133-143.

[20] K. Yoshikawa, Controlling the higher-order structure of giant DNA molecules, Adv. Drug Deliv. Rev. 52 (3) (2001) 235-244.

[21] C. Moran, et al., Chemical structure/property relationship in single-chain arginine surfactants, Langmuir 17 (16) (2001) 5071-5075.

[22] D.D. Lasic, Novel applications of liposomes, Trends Biotechnol. 16 (7) (1998) 307-321.

[23] M.R. Infante, A. Pinazo, J. Seguer, Non-conventional surfactants from amino acids and glycolipids: structure, preparation and properties, Colloids Surf. Physicochem. Eng. Asp. 123 (1997) 49-70.

[24] C. Moran, et al., "Green" amino acid-based surfactants, Green Chem. 6 (5) (2004) 233-240.

[25] J. Sambrook, E.F. Fritsch, T. Maniatis, Molecular Cloning: A Laboratory Manual, Cold Spring Harbor Laboratory Press, New York, 1989.

[26] W. Saenger, Principles of Nuclei Structure, Springer-Verlag, New York, 1984.

[27] Y. Matsuzawa, K. Yoshikawa, Change of the higher-order structure in a giant DNA induced By 4',6-diamidino-2-phenylindole as a minor-groove binder and ethidium-bromide as an intercalator, Nucleos. Nucleot. 13 (6-7) (1994) 1415-1423.

[28] S.M. Mel'nikov, et al., Phase behavior of single DNA in mixed solvents, J. Am. Chem. Soc. 121 (6) (1999) 1130-1136.

[29] J.R. Bellare, et al., Controlled environment vitrification system-an improved sample preparation technique, J. Electron Microsc. Tech. 10 (1) (1988) 87-111.

[30] Y. Talmon, Transmission electron microscopy of complex fluids: the state of the art, Berichte Der Bunsen-Gesellschaft-Phys. Chem. Chem. Phys. 100 (3) (1996) 364-372.

[31] M. Adrian, et al., Cryo-electron microscopy of viruses, Nature 308 (5954) (1984) 32-36. 
[32] Å. Johansson, B. Lindman, Nuclear magnetic resonance spectroscopy of liquid crystals-amphiphilic systems, in: G.W. Gray, P.A. Winsor (Eds.), Liquid Crystals \& Plastic Crystals, Ellis Horwood Limited, Chichester, 1974, pp. 192-230.

[33] J. Ulmius, H. Wennerstrom, Proton NMR bandshapes for large aggregates - micellar solutions of hexadecyltrimethylammonium bromide, J. Magn. Reson. 28 (2) (1977) 309-312.

[34] M. Rosa, M. Rosa Infante, M.d.G. Miguel, B. Lindman, Spontaneous formation of vesicles and dispersed cubic and hexagonal particles in amino acid-based catanionic surfactant systems, Langmuir 22 (13) (2006) $5588-5596$.

[35] E.K. Wasan, et al., A multi-step lipid mixing assay to model structural changes in cationic lipoplexes used for in vitro transfection, Biochim. Et Biophys. Acta-Biomembr. 1461 (1) (1999) 27-46.

[36] A. Yaghmur, et al., Emulsified microemulsions and oil-containing liquid crystalline phases, Langmuir 21 (2) (2005) 569-577.

[37] M.M. Breuer, I.D. Robb, Interactions between macromolecules and detergents, Chem. Ind. (13) (1972) 530-535.

[38] D.F. Evans, H. Wennerstrom, The Colloidal Domain-Where Physics, Chemistry, Biology and Technology Meet, 2nd ed., Wiley-VCH, New York, 1999.

[39] K. Holmberg, et al., Surfactants and Polymers in Aqueous Solution, 2nd ed., John Wiley \& Sons Ltd., West Sussex, 2003.

[40] J.O. Radler, et al., Structure of DNA-cationic liposome complexes: DNA intercalation in multilamellar membranes in distinct interhelical packing regimes, Science 275 (5301) (1997) 810-814.

[41] B.J. Battersby, et al., Evidence for three-dimensional interlayer correlations in cationic lipid-DNA complexes as observed by cryo-electron microscopy, Biochim. Et Biophys. Acta-Biomembr. 1372 (2) (1998) 379-383.

[42] Y.S. Mel'nikova, S.M. Mel'nikov, J.E. Lofroth, Physico-chemical aspects of the interaction between DNA and oppositely charged mixed liposomes, Biophys. Chem. 81 (2) (1999) 125-141.

[43] S. Audouy, D. Hoekstra, Cationic lipid-mediated transfection in vitro and in vivo, Mol. Membr. Biol. 18 (2) (2001) 129-143.
[44] J.O. Radler, et al., Structure and interfacial aspects of self-assembled cationic lipid-DNA gene carrier complexes, Langmuir 14 (15) (1998) 4272-4283.

[45] I. Koltover, et al., An inverted hexagonal phase of cationic liposome-DNA complexes related to DNA release and delivery, Science 281 (5373) (1998) $78-81$.

[46] C. Leal, et al., The hydration of a DNA-amphiphile complex, J. Phys. Chem. B 108 (9) (2004) 3044-3050.

[47] C. Leal, et al., NMR studies of molecular mobility in a DNA-amphiphile complex, J. Phys. Chem. B 108 (39) (2004) 15392-15397.

[48] R.R. Balmbra, J.S. Clunie, J.F. Goodman, Cubic mesomorphic phases, Nature 222 (5199) (1969) 1159.

[49] K. Fontell, Cubic phases in surfactant and surfactant-like lipid systems, Colloid Polym. Sci. 268 (3) (1990) 264.

[50] K. Thalberg, B. Lindman, K. Bergfeldt, Phase behavior of systems of polyacrylate and cationic surfactants, Langmuir 7 (1991) 2893-2898.

[51] K. Thalberg, B. Lindman, G. Karlstrom, Phase-behavior of a system of cationic surfactant and anionic polyelectrolyte - the effect of salt, J. Phys. Chem. 95 (15) (1991) 6004-6011.

[52] J.O. Carnali, (Polymer polymer)-like phase-behavior in the system tetradecyltrimethylammonium bromide sodium polyacrylate water, Langmuir 9 (11) (1993) 2933-2941.

[53] E.F. Marques, et al., Interactions between catanionic vesicles and oppositely charged poly electrolytes-phase behavior and phase structure, Macromolecules 32 (20) (1999) 6626-6637.

[54] M. Skepo, P. Linse, Complexation, phase separation, and redissolution in polyelectrolyte-macroion solutions, Macromolecules 36 (2) (2003) $508-519$.

[55] J. Gustafsson, et al., Complexes between cationic liposomes and DNA visualized by cryo-TEM, Biochim. Et Biophys. Acta-Biomembr. 1235 (2) (1995) 305-312.

[56] S. Huebner, et al., Lipid-DNA complex formation: reorganization and rupture of lipid vesicles in the presence of DNA as observed by cryoelectron microscopy, Biophys. J. 76 (6) (1999) 3158-3166. 